\title{
The treatment of trismus with Ativan: a 3-year-old with difficulty opening her mouth
}

\author{
Erin Finn, ${ }^{1}$ Laura Cannon, ${ }^{2}$ Katherine A Jordan ${ }^{2}$
}

'Department of Pediatrics, University of North Carolina at Chapel Hill, Chapel Hill, North Carolina, USA

UNC Health Care System, Chapel Hill, North Carolina, USA

\section{Correspondence to}

Dr Laura Cannon,

LauraACannon86@gmail.com

Accepted 31 May 2018

\section{DESCRIPTION}

A 3-year-old healthy girl presented with intermittent spells of difficulty opening her mouth, talking and swallowing.

Episodes began 3 weeks prior without any inciting incident. Initially occurring weekly, episodes were brief and self-resolving, but had begun increasing in frequency. Symptoms were typically worse later in the day. The presenting episode started 36 hours earlier. The child was eating when her jaw unexpectedly clenched tightly, preventing her from chewing, swallowing or opening her mouth. She had no other neurological symptoms. Family denied any new exposures or trauma. She had no other systemic symptoms. Her father had severe blepharospasms in youth that resolved without treatment.

Her mouth was pursed and jaw tightly clenched (figures 1 and 2). She was drooling and appeared unable to swallow secretions or speak, though was whining and appeared frustrated. Temporomandibular joint (TMJ) was non-tender with symmetrical jaw musculature. She had fasciculations over her chin. Remainder of her examination was unremarkable.

Neck radiographs and CT were normal. MRI brain, electroencephalogram (EEG) and cerebral spinal fluid (CSF) analysis were unremarkable. No autoimmune, infectious, or paraneoplastic aetiology was identified. The patient was treated with diphenhydramine without improvement. She received lorazepam with rapid resolution of symptoms (figure 3). Symptoms returned 24 hours later, and she again got lorazepam with resolution. She

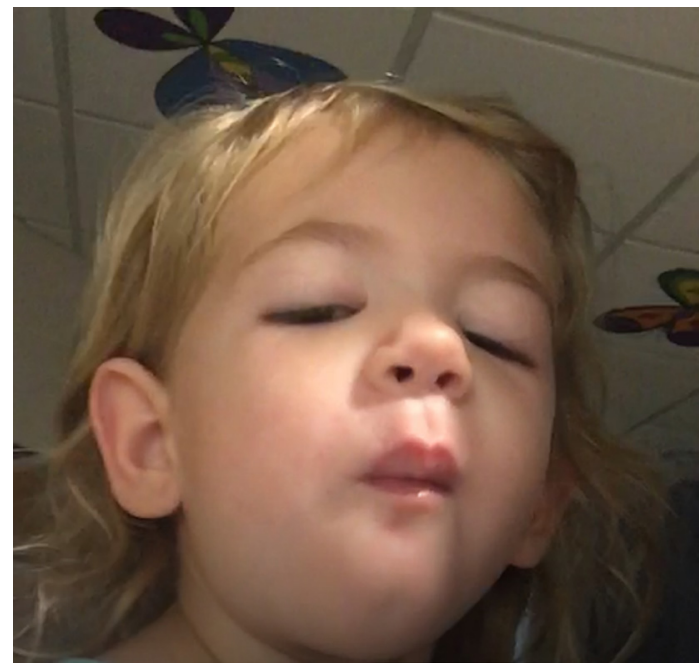

Figure 1 The patient at initial presentation with pursed lips and difficulty opening her mouth.

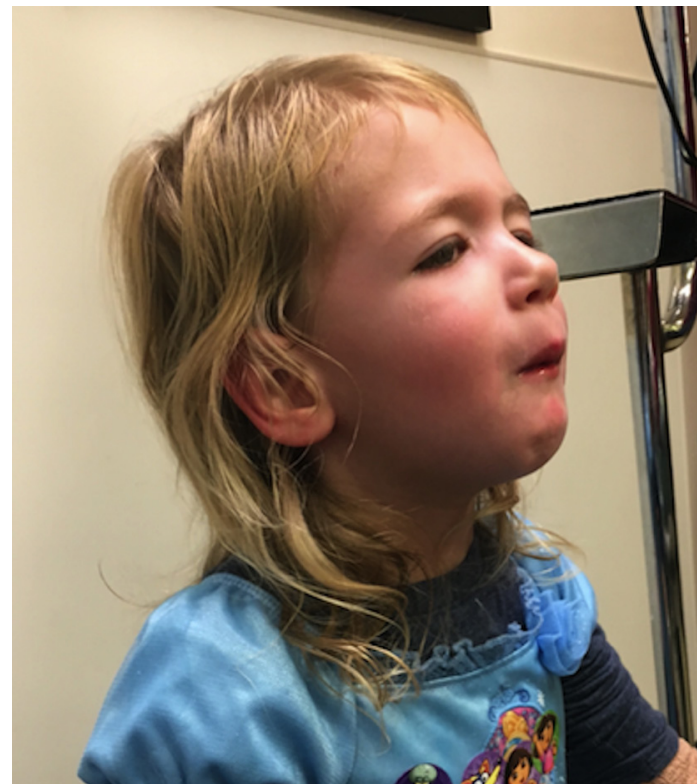

Figure 2 Profile of the patient at initial presentation.

was diagnosed with oromandibular dystonia and discharged on clobazam with no episodes after discharge. Clobazam was tapered after 6 months. She continues to do well.

The general paediatrician should recognise dystonia which is characterised by sustained or intermittent muscle contractions resulting in abnormal movements and postures. Oromandibular dystonia is a specific form with involuntary contraction of the masticatory, lingual and pharyngeal

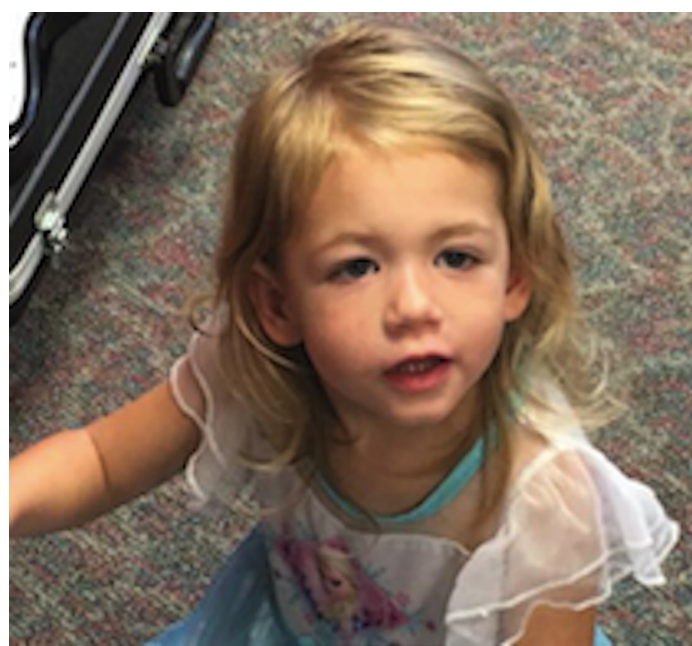

Figure 3 The patient with resolution of her symptoms after treatment with lorazepam. 
Written by the patient's mother (edited with patient identifiers removed):

In October 2016, our 3-year-old daughter was gearing up for Halloween. We noticed over the course of the month she was scratching her chin, nose and forehead quite a bit, and assumed it was just a nervous reaction to noise and light. But, it progressed. Her forehead scratching got so bad that any photo we took of her it showed.

The week after Halloween, she started to refuse to eat and would keep her mouth shut for different periods of time. We thought it was her just being a toddler and not liking her dinner, but 1 day she went for hours not eating — which is not normal for her. The scratching and itching also continued. We thought it may have been her molars coming in, or a viral illness she picked up from school. Something related to pain that was short term. We never even conceived that it was because she physically couldn't open her mouth. Over the next week, she would routinely keep her mouth shut for a couple hours, then half a day, also sometimes drooling. It wasn't consistent, or every day.

After a week, we decided to go to her pediatrician's office. The first visit was no help — and the doctor we met with actually said that she had a psychological issue and that's why she was choosing to keep her mouth shut. So then we took her to a dentist. He said it may have been hand, foot, mouth disease. While at that appointment, she wouldn't open her mouth (turns out it was because she couldn't), so he wasn't able to see inside to determine what was going on. The next day, we went back to the pediatrician's office-this time to a different doctor. She gave a prescription for a mouthwash to help with sores-still not fully sure as to what was going on.

The next day, things got bad. She had gone almost a full day with her mouth closed and was-what we thought-totally refusing to eat or drink. I started to syringe milk and water into her mouth, and massage it down her throat. We went to a local ER that evening, and spent the night. The on-call doctor diagnosed her with TMJ, and she was kept overnight given fluids and medication to relax her mouth.

Two days later, on a Saturday morning, she woke up and her mouth was shut. Without hesitation, we immediately packed a bag and headed to UNC Children's Hospital in Chapel Hill, NC. Within 10 min of arriving to the ER, she was in a room, being evaluated by the on-call doctor. She was administered fluids and was seen by two more doctors, including Dr. Erin Finn, who determined that she may have a neurological disorder. Within a few hours, she was admitted, and they prescribed Benadryl, to see if it was an allergic reaction. She woke up the next morning, able to eat and talk, but her mouth quickly locked up again.

After additional testing, and evaluation from pediatric neurology, it was determined that she had a neurological movement disorder called dystonia. She has oromandibular dystonia, which affects her mouth, throat and jaw. When she has an 'episode', she's unable to talk, eat, drink or swallow. Her mouth, throat and jaw go into muscle spasms and she's physically unable to open her mouth or swallow. They told us that her case was extremely rare-so knowing that, and knowing how quickly they could identify the illness was outstanding. She was administered Ativan, and within a couple hours her mouth relaxed and she was able to eat and talk again.

She spent a week in the pediatric seizure unit and went through multiple tests, including X-rays, CT scan, MR, lumbar puncture, blood work and an EEG. Luckily, all the tests came back clear. What was so outstanding to us was the care she received. We worked directly with her medical team, and loved how for each of her hospital check-ups (which was frequently) we would have a wide array of doctors and specialists in the room, a collaborative and integrative approach. Everyone played a role from the doctors, to the cleaning woman-who one evening, brought her a book and sat and read it with her!

After about a week, she was discharged and sent home with instructions to take Onfi daily. She's had several check-ups since that time with pediatric neurology, and we are happy to report that she is off of her antiseizure medication and hasn't had any episodes since her hospital stay. The future is unpredictable, but we're comforted knowing that we have the UNC team in our corner to help.

muscles. Although typically occurring in middle-aged adults, it can be diagnosed in children. It is typically idiopathic but can be associated with medications, autoimmune disease or intracranial process. ${ }^{1}$ Often initially misdiagnosed, diagnosis is made based on the characteristic clinical presentation with symptoms often absent in the morning and triggered by speaking or chewing. ${ }^{2}$

There is no standard treatment, but recognised treatments include botulinum toxin injection, benzodiazepines,

\section{Learning points}

- Although the disorder is more common in middle-aged adults, the general paediatrician should recognise the presentation of oromandibular dystonia which is characterised by sustained or intermittent muscle contractions resulting in abnormal movements and postures.

- Possible treatments include botulinum toxin injection, benzodiazepines, anticholinergic or dopaminergic drugs, and muscle relaxant, though standardisation of treatment is difficult given the rarity of the disease.

- Paediatricians should consider genetic causes in young children presenting with dystonia and take a thorough family history. anticholinergic or dopaminergic drugs, and muscle relaxants. ${ }^{3}$ The aetiology of dystonia is not well understood but is hypothesised to involve dopamine transmission and the basal ganglia. There are known genetic causes, and a genetic cause is more often identified in early onset dystonia. ${ }^{2}$

Acknowledgements We would like to acknowledge the patient's mother, Cathleen Schmonsees for allowing us to care for her child and providing her perspective to our submission.

Contributors EF: developed the initial draft of this submission. KAJ and LC: revised and edited it. All of the authors approved the final copy of this submission for publication.

Funding The authors have not declared a specific grant for this research from any funding agency in the public, commercial or not-for-profit sectors.

Competing interests None declared.

Patient consent Parental/guardian consent obtained.

Provenance and peer review Not commissioned; externally peer reviewed.

\section{REFERENCES}

1 Yoshida K. Sensory trick splint as a multimodal therapy for oromandibular dystonia. J Prosthodont Res 2018;62:239-44.

2 Jinnah HA, Factor SA. Diagnosis and treatment of dystonia. Neuro/ Clin 2015:33:77-100.

3 Gautam P, Bhatia MS, Kaur J, et al. Meige's syndrome. Ind Psychiatry J 2016;25:232-3. 
Copyright 2018 BMJ Publishing Group. All rights reserved. For permission to reuse any of this content visit http://group.bmj.com/group/rights-licensing/permissions.

BMJ Case Report Fellows may re-use this article for personal use and teaching without any further permission.

Become a Fellow of BMJ Case Reports today and you can:

- Submit as many cases as you like

- Enjoy fast sympathetic peer review and rapid publication of accepted articles

Access all the published articles

Re-use any of the published material for personal use and teaching without further permission

For information on Institutional Fellowships contact consortiasales@bmjgroup.com

Visit casereports.bmj.com for more articles like this and to become a Fellow 